OPEN ACCESS

Edited by:

Xicai Sun,

Fudan University, China

Reviewed by:

Tomasz Dziedzic,

Medical University of Warsaw, Poland

Ye Gu,

Fudan University, China Renzhi Wang,

Peking Union Medical College Hospital (CAMS), China

*Correspondence:

Tao Hong

ht2000@vip.sina.com

${ }^{\dagger}$ These authors have contributed equally to this work

Specialty section: This article was submitted to Surgical Oncology, a section of the journal

Frontiers in Oncology

Received: 09 April 2021 Accepted: 20 May 2021 Published: 21 June 2021

Citation:

Ouyang $T$, Zhang $N$, Xie S, Tang B, Li J, Xiao L, Zhang F, Wu B, Zhou D,

Li M and Hong T (2021) Outcomes and Complications of Aggressive

Resection Strategy for Pituitary Adenomas in Knosp Grade 4 With Transsphenoidal Endoscopy.

Front. Oncol. 11:693063. doi: 10.3389/fonc.2021.693063

\section{Outcomes and Complications of Aggressive Resection Strategy for Pituitary Adenomas in Knosp Grade 4 With Transsphenoidal Endoscopy}

\author{
Taohui Ouyang ${ }^{1+}$, Na Zhang ${ }^{2 \dagger}$, Shenhao Xie ${ }^{1}$, Bin Tang ${ }^{1}$, Junjun $\mathrm{Li}^{3}$, Limin Xiao ${ }^{1}$, \\ Fabao Zhang ${ }^{4}$, Bowen $\mathrm{Wu}^{1}$, Dongwei Zhou ${ }^{1}$, Meihua $\mathrm{Li}^{1}$ and Tao Hong ${ }^{1 *}$ \\ 1 Department of Neurosurgery, the First Affiliated Hospital of Nanchang University, Nanchang, China, ${ }^{2}$ Department of \\ Neurology, the First Affiliated Hospital of Nanchang University, Nanchang, China, ${ }^{3}$ Department of Neurosurgery, Wuhan \\ Union Hospital, Wuhan, China, ${ }^{4}$ Department of Radiology, the First Affiliated Hospital of Nanchang University, Nanchang, China
}

Surgery for pituitary adenomas (PAs) with cavernous sinus (CS) invasion in Knosp grade 4 is a great challenge and whether to adopt a conservative or aggressive surgical strategy is controversial. The aim of this study is to provide the outcomes and complications of an aggressive resection strategy for Knosp grade 4 PAs with transsphenoidal endoscopic surgery. Outcomes and complications were retrospectively analyzed in 102 patients with Knosp grade 4 PAs. Among them, primary PAs were seen in 60 patients and recurrent PAs were seen in 42 cases. Gross total resection (GTR) of the entire tumor was achieved in 72 cases (70.6\%), subtotal tumor resection (STR) in 18 cases (17.6\%), and partial tumor resection (PTR) in 12 cases (11.8\%). Additionally, GTR of the tumor within the CS was achieved in 82 patients (80.4\%), STR in 17 patients (16.7\%), and PTR in 3 patients (2.9\%). Statistical analyses showed that both recurrent tumors and firm consistency tumors were adverse factors for complete resection $(\mathrm{P}<0.05)$. Patients with $\mathrm{GTR}$ of the entire tumor were more likely to have favorable endocrine and visual outcomes than those with incomplete resection $(\mathrm{P}<0.05)$. Overall, the most common surgical complication was new cranial nerve palsy $(n=7,6.8 \%)$. The incidence of internal carotid artery (ICA) injury and postoperative cerebrospinal fluid (CSF) leakage was 2.0\% $(n=2)$ and 5.9\% $(n=6)$, respectively. Six patients (5.9\%) experienced tumor recurrence postoperatively. For experienced neuroendoscopists, an aggressive tumor resection strategy via transsphenoidal endoscopic surgery may be an effective and safe option for Knosp grade 4 PAs.

Keywords: endoscopic, cavernous sinus, pituitary adenoma, outcome, surgery

\section{INTRODUCTION}

Pituitary adenomas (PAs) are the third most common primary intracranial tumor, following meningiomas and gliomas, accounting for about $10 \%$ to $25 \%$ of intracranial tumors $(1,2)$. Some PAs invade surrounding structures such as the diaphragma sellae, the sphenoid sinus, and the cavernous sinus (CS), with approximately $10 \%$ involving the CS $(3,4)$. PAs invading the CS are particularly surgically challenging due to their close proximity to critical neurovascular structures and their deep intracranial location. 
For PAs with CS invasion, surgical approaches include transcranial microscopy, transsphenoidal microscopy, and transsphenoidal endoscopy. Transcranial microscopy is a "lateral to medial" approach that basically entails entering from the lateral wall of the CS where multiple cranial nerves are located $(5,6)$. In addition, surgical visualization when utilizing the transcranial microscopy approach is often insufficient. These disadvantages support the argument that transcranial microscopic surgery is not an ideal approach for the removal of PAs with CS invasion. Since its introduction, the transsphenoidal approach has been continuously refined and popularized, and to date is the most common approach for PAs. Transsphenoidal approach is a "medial to lateral" approach that enters the CS through the medial CS wall, thereby avoiding direct obstruction by the cranial nerves within the lateral CS wall. Moreover, PAs invade the CS in a medial to lateral direction, often pushing the CS contents medially to laterally. Therefore, the transsphenoidal approach is an excellent and logical route for the removal of PAs within the CS through the medial CS wall. However, certain limitations such as a narrow surgical corridor and insufficient visualization, confine use of the transsphenoidal microscopic approach to those PAs with mild CS invasion (Knosp grades 1-2) (7). Compared with transsphenoidal microscopy, transsphenoidal endoscopic surgery not only improves surgical visualization, but also provides greater exposure to the lateral CS extension of tumors $(7,8)$. Consequently, transsphenoidal endoscopic surgery is the preferred choice for PAs with severe CS invasion (Knosp grades 3-4) $(9,10)$.

For PAs with severe CS invasion, especially grade 4 PAs, gross total resection (GTR) with transsphenoidal endoscopic surgery still presents a great challenge. To illustrate, Hwang et al. (11) retrospectively examined data on 275 patients with non-functional PAs with CS invasion from 2000-2012, and reported a GTR rate of $5.9 \%$ in transsphenoidal endoscopy for grade 4 PAs. This low GTR rate reflects the conservative strategy regarding tumor resection, but it also indicates that in some cases with grade 4 PAs, GTR can be achieved by transsphenoidal endoscopic surgery. Of note, these cases occurred a decade ago when transsphenoidal endoscopic technology was still in its infancy.

With the recent, rapid development in transsphenoidal endoscopic techniques and advances made through in-depth study of the endoscopic anatomy of the CS $(12,13)$, as well as the availability of intraoperative neuronavigation, doppler ultrasonography, and cranial nerve monitoring, it is worth reconsidering whether it is best to adopt a conservative or aggressive surgical strategy for grade 4 PAs. The current study provides the outcomes and complications of an aggressive surgical strategy for 102 patients with grade 4 PAs treated by transsphenoidal endoscopic surgery performed by the same surgeon.

\section{MATERIALS AND METHODS}

\section{Clinical Materials}

Between January 2014 and August 2020, 908 consecutive patients undergoing transsphenoidal endoscopic surgery for PAs were evaluated. A total of 102 patients were included in this study according to the following criteria: 1) Knosp grade 4 PAs identified jointly by a neuroradiologist and two neurosurgeons; 2) Complete preoperative and postoperative magnetic resonance imaging (MRI) data and follow-up data; and 3) All operations performed by the same neurosurgeon (Tao Hong). A total of 4 cases were excluded due to lack of complete follow-up data. Hospital review board approval was obtained from the Institutional Ethics Committee of the First Affiliated Hospital of Nanchang University.

\section{Neuroradiological Evaluation}

MRI examination was performed for all patients to evaluate tumor size and volume. Tumors with a maximum diameter (MD) of more than $1 \mathrm{~cm}$ were defined as macroadenomas, and tumors with a MD of more than $4 \mathrm{~cm}$ were defined as giant PAs. Tumor volume was approximated by calculations using the sphericity formula $(\mathrm{A} \times \mathrm{B} \times \mathrm{C}) \times \pi / 6$, where $\mathrm{A}, \mathrm{B}$ and $\mathrm{C}$ represent the maximum length in three dimensions of the PA. Extent of resection for the entire tumor and tumors within the CS were analyzed and the extent of resection was then classified into categories: gross-total resection (GTR) (no residual enhancing lesion), subtotal tumor resection (STR) (residual enhancing lesion $\leq 20 \%$ ) and partial tumor resection (PTR) (residual enhancing lesion $>20 \%$ ).

\section{Evaluation of the Internal Carotid Artery (ICA)}

A preoperative balloon occlusion test was used to evaluate the contralateral compensatory capability of the ICA in case of injury. Although the anatomy of the ICA was generally consistent, the shape of the ICA under the influence of the tumor was inconsistent and individualized depending on the tumor location. Preoperatively, three-dimensional (axial, coronal, and sagittal) MRI was used to individually analyze the spatial relationship between the ICA and the CS tumor, and further, to determine the size of the space for each compartment within the CS. For example, when the horizontal ICA was inferior to the tumor, it caused the horizontal ICA to sink due to the depression of the tumor, resulting in a larger posterosuperior compartment and a smaller anteroinferior compartment within the CS. When the horizontal ICA was superior to the tumor, it caused the horizontal ICA to be raised by the tumor, leading to a smaller posterosuperior compartment and a larger anteroinferior compartment within the CS. When the horizontal ICA was in the middle of the tumor, the result was a combination of the above two conditions, leaving large posterosuperior and anteroinferior compartments.

\section{Endoscopic Surgery of PA in Knosp Grade 4}

For PAs invading the CS, transsphenoidal endoscopic surgery mainly included medial (transsphenoidal transsellar) and lateral (transmaxillary transpterygoidal) approaches. The medial approach was used to remove tumors in the posterosuperior and lateral compartments of the CS. The lateral approach, including an anteroinferior approach and a lateral-superior approach, was used to open the pterygopalatine fossa to obtain more exposure, and to remove tumors in the anteroinferior and lateral compartments of the CS. These approaches were shown in Figure 1. An angular endoscope was used to obtain different angles of surgical field visualization, and various other angular instruments were used to 

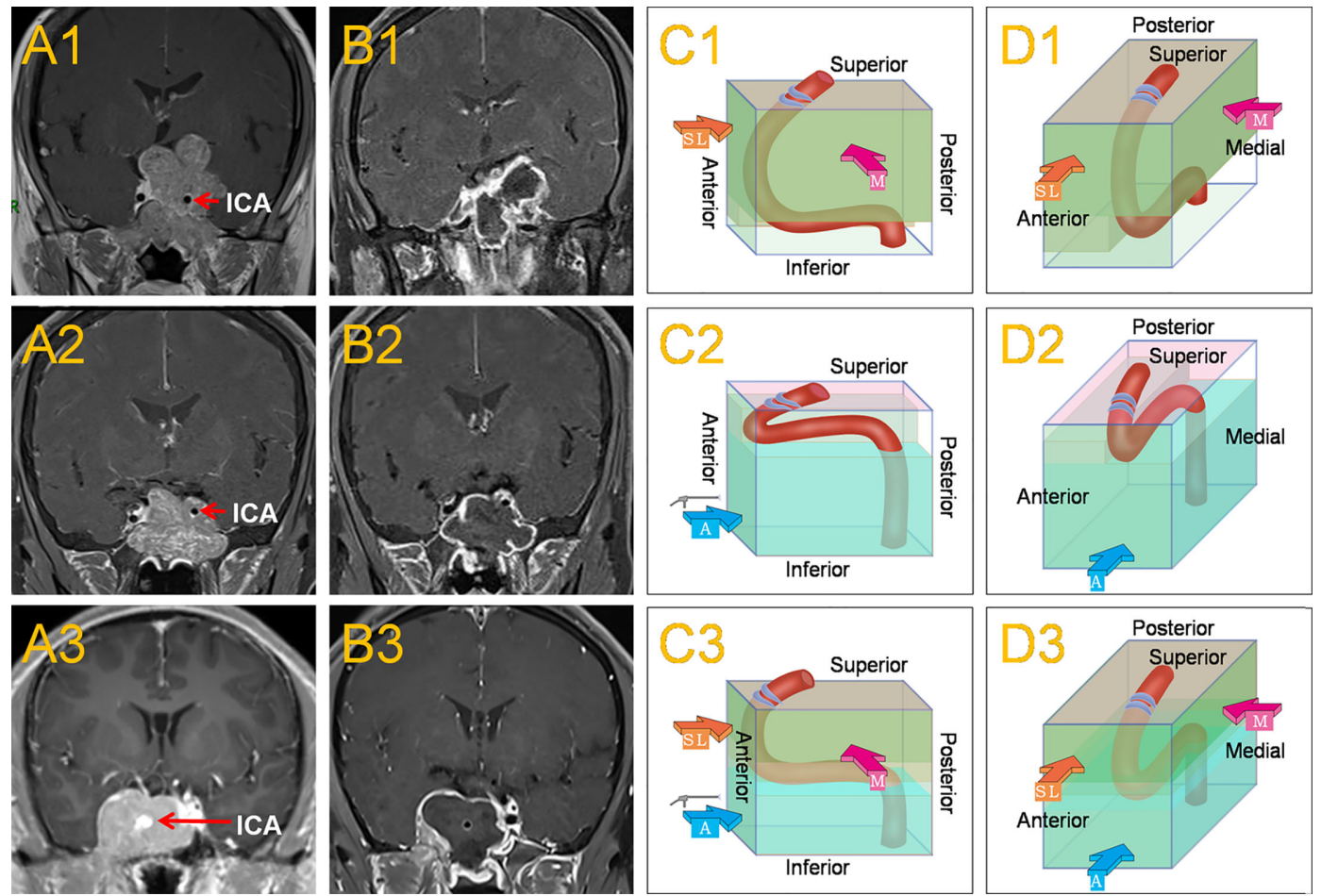

FIGURE 1 | This shows the common location of the horizontal ICA in Knosp grade 4 PAs and the main surgical approaches. When the horizontal ICA was inferior to the tumor (A1), it caused the horizontal ICA to sink due to the oppression of the tumor, resulting in a larger posterosuperior compartment and a smaller anteroinferior compartment within the CS. The medial approach, often combined with the superior-lateral approach was mainly used to remove the tumor (C1, D1). Postoperative MRI revealed a subtotal resection of the tumor (B1). When the horizontal ICA was superior to the tumor (A2), it caused the horizontal ICA to be raised by the tumor, leading to a smaller posterosuperior compartment and a larger anteroinferior compartment within the CS. The anteroinferior approach was mainly used to remove the tumor (C2, D2). Postoperative MRI revealed a total resection of the tumor (B2). When the horizontal ICA was in the middle of the CS tumor (A3), which was a combination of the two conditions, then the medial, superior-lateral, and anteroinferior approaches could be used (C3, D3). Postoperative MRI revealed a total resection of the tumor (B3). The red, thick arrow 'M' represents the medial approach, the orange-yellow, thick arrow 'SL' represents the superior-lateral approach, and the blue, thick arrow ' $A$ ' represents the anteroinferior approach.

assist with the medial and lateral approaches. In many cases, a combination of medial and lateral approaches was required to radically remove the tumor. Intraoperative navigation and doppler ultrasonography were used to assist in determining the exact position and shape of the ICA. Before entering the CS to remove the tumor, the proximal end (paraclivus segment) of the ICA was exposed in order to temporarily block the proximal end in the event of injury to the ICA. Based on these analyses above, the individual spatial relationship among the ICA, the CS tumor, and various compartments of the CS were evaluated in order to determine the point of entry to the CS and the type of surgical approach to take within the CS. For example, when the horizontal ICA was inferior to the tumor, first, the medial wall of the CS was opened into the posterosuperior compartment of the CS, and then a combination of angle endoscopy and the medial approach was used to remove the tumor in the posterosuperior and lateral compartments. With this approach, the tumor extending into the oculomotor nerve triangle of the posterosuperior compartment might remain unresectable; in this case, a combination of the lateral-superior approach and the medial approach was required.
When the horizontal ICA was superior to the tumor, first, the anterior wall of the CS was opened and then the anteroinferior approach was used to remove the tumor in the anteroinferior compartment and a lateral-superior approach was used for removing the tumor in the lateral compartment. When the horizontal ICA was in the middle of the CS tumor, which is a combination of the two conditions, then various approaches could be used. Particularly, in some special cases, such as when the ICA was medial to the tumor, which was common in recurrent tumors, a lateral approach was used to remove the tumor. When the ICA was lateral to the tumor, a medial approach alone was used. During tumor resection, any adhesion between the ICA and the abducens nerve requires sharp dissection to avoid injury to the abducens nerve. Care also needs to be taken to avoid injury to the oculomotor nerve in the removal of tumors within the posterosuperior compartment of the CS or even when extending to the temporal lobe through the oculomotor nerve triangle.

After tumor removal, the multilayered method of fat + artificial dura + fascia lata + pedicled mucosal flap + biological glue was used to reconstruct the sellar floor. For patients at high 
risk of cerebrospinal fluid (CSF) leakage, a lumbar puncture catheter drainage system was used to release CSF to prevent CSF leakage after surgery.

\section{Endocrinological Assessment}

Endocrinological results of all the patients were evaluated preoperatively and at 3 months postoperatively. Hormone remission was based on the following criteria (14-17): for prolactin (PRL)-secreting adenomas, serum PRL $<20 \mathrm{ng} / \mathrm{mL}$ in female patients or, $<15 \mathrm{ng} / \mathrm{mL}$ in male patients; for adrenocorticotropic hormone (ACTH)-secreting adenomas, a serum cortisol nadir of $<2 \mathrm{mg} / \mathrm{dL}$ or normal 24-hour urinary free cortisol test at 3 months; and for growth hormone (GH)secreting tumors, normalization of serum insulin-like growth factor-1 level (IGF-1), basal serum $\mathrm{GH}<2.5 \mathrm{ng} / \mathrm{mL}$, or an oral glucose tolerance test of $0.4 \mathrm{ng} / \mathrm{mL}$. During the test, IGF-1 levels were expressed relative to the upper limit of the patient's normal values for the patient's age and sex. The first choice for the treatment of PRL-secreting adenomas was drugs, and surgical indications were mainly drug-resistant tumors and drug intolerance, and rarely, patient choice.

\section{Visual Assessment}

All patients received preoperative and postoperative formal visual function examinations. During follow-up, a visual examination was performed at 3 months, postoperatively.

\section{Statistical Analysis}

Statistical analyses comparing categorical variables were performed using $\mathrm{X}^{2}$ tests or Fisher's exact tests. A two-tailed $P<0.05$ was considered to be statistically significant. Data were analyzed using SPSS version 25.0 (IBM Corporation, Armonk, New York).

\section{RESULTS}

\section{Patient Population and Clinical Presentation}

The 102 patients in the final analysis included 53 females and 49 males, of mean age 39.1 years (range 24-71 years). Primary PAs were seen in 60 patients and recurrent PAs were seen in 42 cases. Preoperative headache symptoms were seen in 33 patients (32.4\%), visual dysfunction in 38 patients (37.3\%), incidental discovery in 8 patients $(7.8 \%)$, and cranial nerve palsy in 6 patients (5.9\%). The detailed results are shown in Table $\mathbf{1}$.

\section{Neuroradiological Outcomes}

Of the 102 cases, 39 patients had giant PAs and 63 patients had macroadenomas. The median tumor volume in all patients was $23.8 \mathrm{~cm}^{3}$, ranging from $1.63 \sim 182 \mathrm{~cm}^{3}$. In 36 patients, bilateral CS invasion was in grade 4 , while unilateral CS invasion in grade 4 was observed in 66 patients (Table 1).

\section{Extent of Resection}

GTR of the entire tumor was achieved in 72 cases (70.6\%), STR in 18 cases $(17.6 \%)$, and PTR in 12 cases (11.8\%). Figure 2
TABLE 1 | Demographic and clinical characteristics of the 102 patients with pituitary adenomas invading the CS.

\begin{tabular}{|c|c|}
\hline Variables & Value \\
\hline Mean age, years (range) & $39.1(24 \sim 71)$ \\
\hline Females (\%) & $53(52.0)$ \\
\hline \multicolumn{2}{|l|}{ Preoperative manifestation } \\
\hline High hormone level (\%) & $40(39.0)$ \\
\hline Headache (\%) & $33(32.4)$ \\
\hline Visual dysfunction (\%) & $38(37.3)$ \\
\hline Cranial nerve palsy (\%) & $6(5.9)$ \\
\hline Incidental discovery (\%) & $8(7.8)$ \\
\hline \multicolumn{2}{|l|}{ Endocrinological types } \\
\hline Non-functional (\%) & $62(60.8)$ \\
\hline $\mathrm{GH}(\%)$ & $13(12.7)$ \\
\hline GH/PRL mixed (\%) & $10(9.8)$ \\
\hline PRL (\%) & $9(8.8)$ \\
\hline ACTH (\%) & $5(4.9)$ \\
\hline FSH (\%) & $2(2.0)$ \\
\hline TSH (\%) & $1(1.0)$ \\
\hline \multicolumn{2}{|l|}{ Direction of invasion } \\
\hline Bilateral (\%) & $36(35.3)$ \\
\hline Unilateral (\%) & $66(64.7)$ \\
\hline Left (\%) & $35(53.0)$ \\
\hline Right (\%) & $31(47.0)$ \\
\hline \multicolumn{2}{|l|}{ Contralateral (\%) } \\
\hline Knosp 0 (\%) & $19(28.8)$ \\
\hline Knosp 1 (\%) & $17(25.8)$ \\
\hline Knosp 2 (\%) & $14(21.2)$ \\
\hline Knosp 3 (\%) & $16(24.2)$ \\
\hline \multicolumn{2}{|l|}{ Size of tumor } \\
\hline Giant pituitary adenoma & 39 (38.2) \\
\hline Macroadenoma & $63(61.8)$ \\
\hline \multicolumn{2}{|l|}{ Volume of tumor $\left(\mathrm{V}, \mathrm{cm}^{3}\right)$} \\
\hline$V<15$ & $22(21.6)$ \\
\hline $15 \leq \mathrm{V} \leq 30$ & $37(36.3)$ \\
\hline$>30$ & $43(42.1)$ \\
\hline \multicolumn{2}{|l|}{ Previous treatment } \\
\hline No surgery (\%) & $60(58.8)$ \\
\hline Craniotomy (\%) & $5(4.9)$ \\
\hline Transnasal microscopy (\%) & $12(11.8)$ \\
\hline Transnasal endoscopic (\%) & $15(14.7)$ \\
\hline Mixed surgery (\%) & $10(9.8)$ \\
\hline Radiotherapy (\%) & $16(15.7)$ \\
\hline
\end{tabular}

illustrated the GTR of the entire tumor. For tumors within the CS, GTR was achieved in 82 patients (80.4\%), STR in 17 patients (16.7\%), and PTR in 3 patients (2.9\%). The GTR rates of the entire lesion and the CS lesion in the primary tumor were $80 \%$ and $91.7 \%$, respectively, while the GTR rates of the entire lesion and the CS lesion in recurrent tumors were $57.1 \%$ and $64.3 \%$, respectively. These results are shown in Tables 2 and 3. Statistical analyses showed that recurrent tumors and firm consistency tumors had lower GTR rates $(\mathrm{p}<0.05)$. However, no statistical differences were found between tumor size or tumor volume and the extent of resection $(\mathrm{p}>0.05)$. Additionally, there was no statistically significant relationship between extent of resection and postoperative CSF leakage or cranial nerve palsy ( $p>0.05)$. These results are shown in Tables 3 and 4.

\section{Surgical Complications}

Surgical complications were uncommon. Overall, the most common complications were new cranial nerve palsy $(n=7$, 

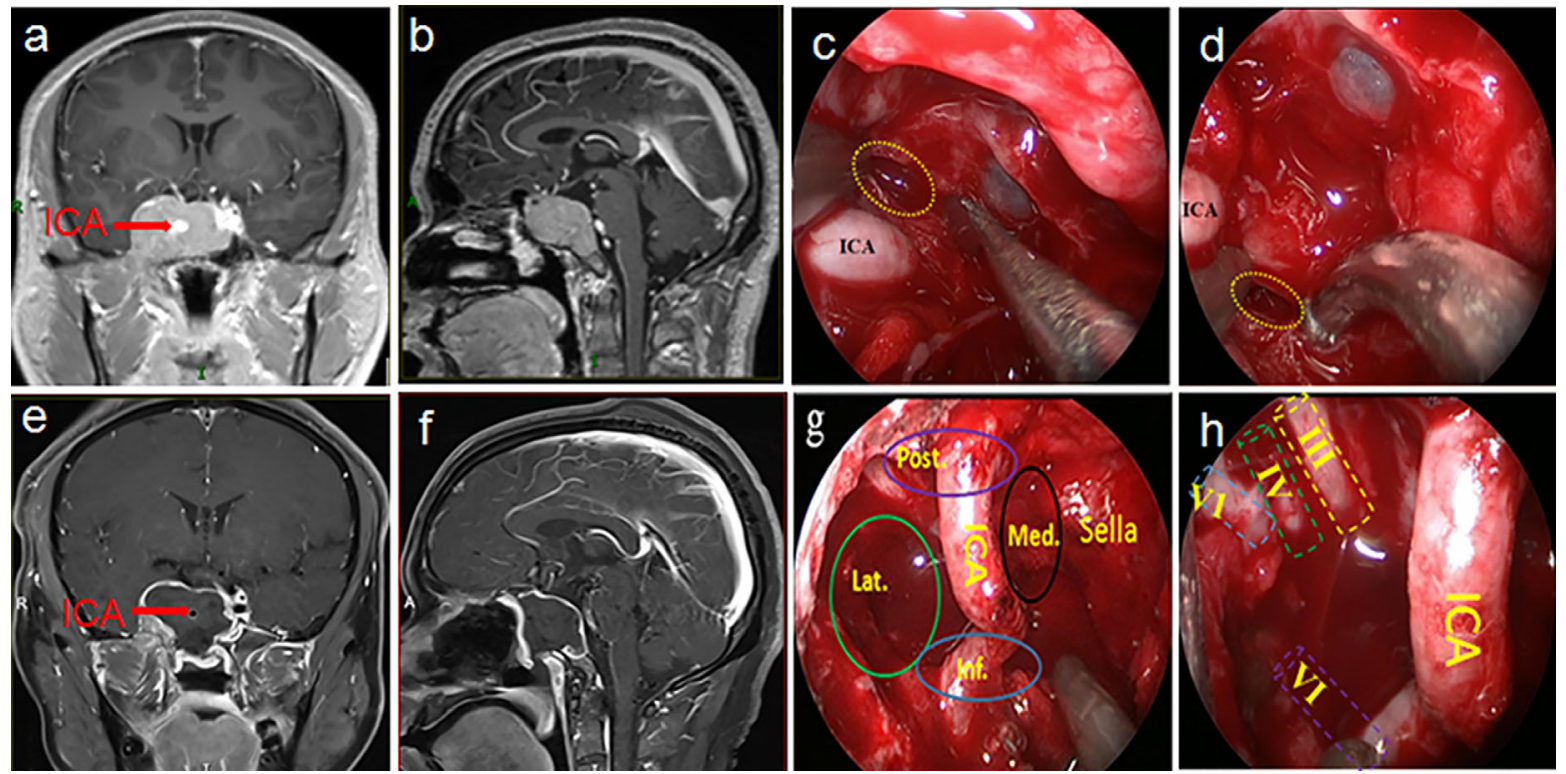

FIGURE 2 | This was a 32-year-old male patient who was admitted to hospital after the accidental discovery of a pituitary tumor due to trauma. The preoperative visual examination was normal, and the preoperative PRL and ACTH hormones were increased. A preoperative MRI (A, B) showed that the tumor was in Knosp grade 4 and was mainly distributed in both posterosuperior and anteroinferior compartments of the CS. Intraoperatively, various compartments (G) and nerves (H) in the CS could be observed after total tumor resection. Postoperative MRI (E, F) also confirmed total tumor resection. The yellow dotted circle indicated entry into the CS from above (C) and below (D) the horizontal ICA. The pathological examination of the tumor was mixed pituitary adenoma. The visual and endocrine function of the patient were all normal three months after the operation. Post., posterior compartment; Med., medial compartment; Lat., lateral compartment; Inf., inferior compartment; ICA, internal carotid artery; III, oculomotor nerve; IV, trochlear nerve; V1, first branch of the trigeminal nerve; VI, abducens nerve.

6.8\%) (Table 5), followed by postoperative CSF leakage $(n=6$, $5.9 \%)$, intracranial infection $(n=5,4.9 \%)$, and ICA injury $(n=2$, 2.0\%). New cranial nerve palsy consisted of oculomotor nerve and abducens nerve palsy, with an incidence of $3.9 \%$ and $2.9 \%$, respectively. For the two patients with ICA injury, the injured ICA was completely clipped in one patient, and the ICA wall was electrocoagulated in the other patient. During the follow-up period, both patients underwent cerebral angiography; no pseudoaneurysm formation was found, and no obvious symptoms were observed. CSF leakage occurred in 6 patients and was managed by lumbar puncture catheter drainage in 2 patients and endoscopic repair surgery in the remaining 4 cases. Of the 5 patients with intracranial infection, 4 patients recovered through the use of antibiotics and lumbar puncture catheter drainage, and the remaining 1 patient died of infection.

\section{Endocrinological Outcomes}

Of the 102 patients, 40 cases (39.2\%) were classified as functional PAs, and hormone remission was seen in 29 of these 40 patients (72.5\%), postoperatively. Statistical analysis showed no statistical differences between endocrine outcomes and tumor size, tumor recurrence, or extent of CS lesion $(p>0.05)$. However, for the entire tumor, patients with GTR had better endocrine outcomes than those with incomplete resection, and the difference was statistically significant $(\mathrm{p}=0.028)$. These results are shown in Table 6.

\section{Visual Outcomes}

Preoperative visual dysfunction was found in 38 patients, of which 28 patients $(73.7 \%)$ improved postoperatively. For the entire tumor, the visual improvement rate was $90.9 \%$ in the GTR group, compared with $63.6 \%$ in the STR group and $20.0 \%$ in the PTR group. The difference between the three groups was statistically significant $(\mathrm{p}=0.003)$. However, preoperative visual function, extent of resection of CS lesion, tumor size, tumor volume, tumor recurrence or tumor consistency were not significantly associated with postoperative visual outcomes ( $\mathrm{p}>0.05)$. These results are shown in Table 7 .

\section{Follow-Up Results}

The follow-up period was 7-87 months, with an average of 46 months. Postoperatively, of the 30 patients with incomplete tumor resection, 5 patients with functional PAs received medical treatment and 12 patients (1 patient with functional $\mathrm{PA}$ and 11 patients with non-functional PAs) received radiotherapy. Among the 7 patients with postoperative new cranial nerve palsy, improvement was observed in 3 patients. For the 6 patients with preoperative cranial nerve palsy, improvement was seen in 4 patients. Six patients, including four patients with PTR, one with STR and one with GTR, experienced tumor recurrence and accepted reoperation. The follow-up methods were conducted through outpatient visits and telephone calls. 
TABLE 2 | Surgical results and postoperative complications in the 102 patients who underwent transsphenoidal endoscopic surgery for pituitary adenomas in Knosp Grade 4

\begin{tabular}{|c|c|}
\hline Variable & Value \\
\hline \multicolumn{2}{|l|}{ Extent of resection } \\
\hline GTR (\%) & $72(70.6)$ \\
\hline STR (\%) & $18(17.6)$ \\
\hline PTR (\%) & $12(11.8)$ \\
\hline \multicolumn{2}{|l|}{ Extent of CS resection } \\
\hline GTR (\%) & $82(80.4)$ \\
\hline STR (\%) & $17(17.6)$ \\
\hline PTR (\%) & $3(2.0)$ \\
\hline \multicolumn{2}{|l|}{ Intraoprative variables } \\
\hline Mean operation time (min) & 158.5 \\
\hline Mean intraoperative hemorrhage (ml) & 456.7 \\
\hline Firm consistency (\%) & $31(30.4)$ \\
\hline ICA rupture (\%) & $2(2.0)$ \\
\hline CSF leakage (\%) & $11(10.8)$ \\
\hline \multicolumn{2}{|l|}{ Postoperative variables } \\
\hline Headache & 33 \\
\hline Better (\%) & $22(66.7)$ \\
\hline No change (\%) & $11(33.3)$ \\
\hline Visual dysfunction & 38 \\
\hline Better (\%) & $28(73.7)$ \\
\hline No change (\%) & $10(26.3)$ \\
\hline Hormone remission & 40 \\
\hline Yes (\%) & $29(72.5)$ \\
\hline No (\%) & $11(27.5)$ \\
\hline \multicolumn{2}{|l|}{ Postoperative complications } \\
\hline abducens nerve palsy (\%) & $3(2.9)$ \\
\hline oculomotor nerve palsy (\%) & $4(3.9)$ \\
\hline CSF leakage (\%) & $6(5.9)$ \\
\hline CNS infection (\%) & $5(4.9)$ \\
\hline Monocular blindness (\%) & $2(2.0)$ \\
\hline Panhypopituitarism (\%) & $3(2.9)$ \\
\hline Permanent diabetes insipidus (\%) & $2(2.0)$ \\
\hline \multicolumn{2}{|l|}{ Follow-up treatments } \\
\hline Radiotherapy (\%) & $12(11.8)$ \\
\hline Medical therapy (\%) & $5(4.9)$ \\
\hline Recurrence (\%) & $6(5.9)$ \\
\hline
\end{tabular}

GTR, gross total resection; STR, subtotal tumor resection; PTR, partial tumor resection; CS, cavernous sinus; CSF, cerebrospinal fluid; CNS, Central Nervous System; ICA, Internal carotid artery.

\section{DISCUSSION}

\section{Outcomes of Aggressive Tumor Resection Extent of Resection}

This study outlines the surgical outcomes and experiences of 102 patients with grade 4 PAs who underwent endoscopic transsphenoidal surgery. To date, this is the largest study conducted on grade $4 \mathrm{PAs}$, and is the first study to specifically focus on functional and non-functional grade 4 PAs. One of the study's strengths is that all of the surgeries in this study were performed by the same surgeon, eliminating variability and rendering more credibility to the study results. Management of the intracavernous ICA contributes to some of the challenges surrounding the surgical removal of grade 4 PAs. To address this, individual spatial relationships among the ICA, the CS tumor, and various compartments of the CS were evaluated in detail preoperatively, and different CS approaches were adopted, accordingly. For example, when the horizontal ICA was superior to the tumor, the anterior wall of the CS was opened, and then an anteroinferior approach was used to remove the tumor from within the anteroinferior compartment, while a lateral-superior approach was used to remove the tumor from within the lateral compartment. This study represents the first time that these methods were carried out for grade 4 PAs. In this study, an aggressive resection strategy was adopted, not only for tumors in the medial CS, but also for tumors in the lateral CS. This approach differs from the previous surgical resection strategies of Woodworth et al. (18) and Toda et al. (19). Their surgical concept included using an aggressive strategy for tumors in the medial CS and a conservative strategy for tumors in the lateral CS. Both reported GTR rates for grade 4 PAs of no more than $10 \%$. However, our study reported a GTR rate of $70.6 \%$, which is significantly higher than the GTR rates (from 0 to $53.8 \%$ ) reported in the previous literature (19-27) (Table 8). Of note, while we adopted an aggressive tumor resection strategy to obtain a considerable GTR rate, the incidence of surgical complications was still within an acceptable range. This indicates the feasibility and efficacy of aggressive resection strategy via transsphenoidal endoscopic surgery for grade 4 PAs.

\section{Factors Influencing the Extent of Resection}

The factors that influence the extent of resection for grade 4 PAs are unclear, because no previous study has ever specifically examined these potential factors. Any previous studies that did report on potential factors influencing the extent of resection included common PAs without CS invasion, or invasive PAs with varying extents of CS involvement. Chabot et al. (28) found that factors influencing the extent of resection included tumor recurrence, preoperative hormone replacement therapy, and Knosp grade. Bao et al. (24) also found that tumor recurrence and high Knosp grade were adverse factors affecting the extent of resection. In our study, we analyzed various potential factors, including tumor recurrence, tumor size, tumor volume, and tumor consistency, and found that tumor recurrence and consistency affected the extent of resection, while the other factors did not. In addition, we also found that there was no statistical correlation between the extent of tumor resection and the occurrence of CSF leakage and postoperative cranial nerve palsy $(\mathrm{P}>0.05)$.

\section{Visual Outcome}

In a 2012 systematic review by Komotar et al. (29), those patients who underwent transsphenoidal microscopic approach showed that the rate of visual improvement after PA surgery was $34.8 \%$. Kalinin et al. (25) reported on a transsphenoidal endoscopic study of 97 patients with PAs invading CS in 2016, and vision improvement was achieved in $41.4 \%$ of cases. In a study of 39 patients with transsphenoidal endoscopic surgery, Chabot et al. (28) reported that 31 had CS invasion and the improvement rates of visual acuity and visual field were $73.9 \%$ and $72.4 \%$, respectively. In our study, of the 38 patients who had visual impairment before surgery, visual improvement was achieved in 28 patients (73.7\%), postoperatively. The visual results in our study were better than those reported for transsphenoidal 
TABLE 3 | Surgical results and postoperative complications stratified by primary and recurrent pituitary adenomas.

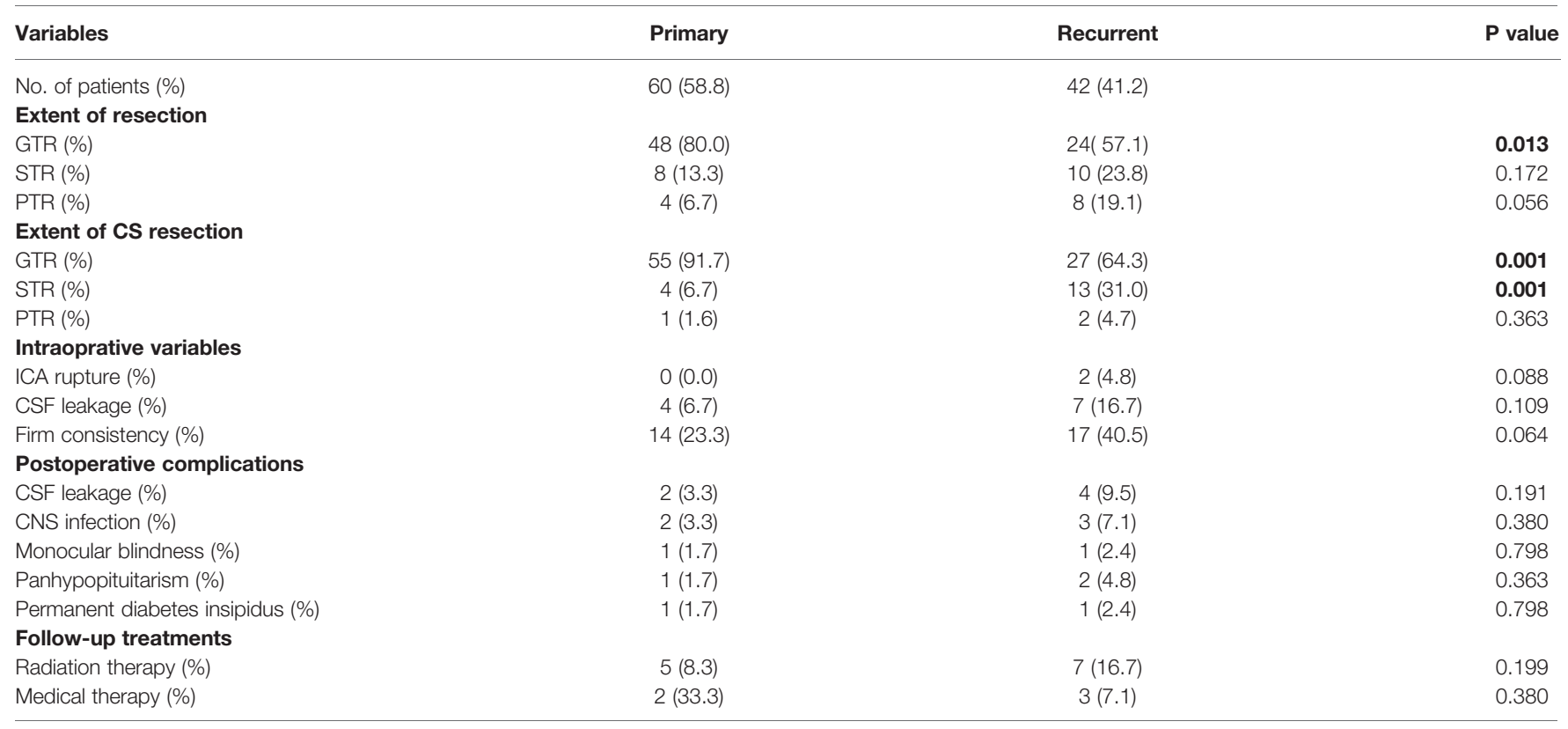

CS, cavernous sinus; CSF, cerebrospinal fluid; GTR, gross total resection; STR, subtotal tumor resection; PTR, partial tumor resection; CNS, central nervous system; ICA: internal carotid artery.

In bold: represent statistical significance.

TABLE 4 | Extent of resection correlated with multiple potential variables.

\begin{tabular}{|c|c|c|c|c|c|c|}
\hline Variables & \multicolumn{3}{|c|}{ Within the CS } & \multicolumn{3}{|c|}{ Entire tumor } \\
\hline \multicolumn{7}{|l|}{ Size of tumor } \\
\hline Macroadenoma & $51(62.2)$ & $10(58.8)$ & 0.795 & $44(61.1)$ & $9(50.0)$ & 0.391 \\
\hline \multicolumn{7}{|c|}{ Volume of tumor( $\left(\mathbf{V} \mathrm{cm}^{3}\right)$} \\
\hline$V<15$ & $19(23.2)$ & $3(17.6)$ & & $16(22.2)$ & $4(22.2)$ & \\
\hline \multicolumn{7}{|c|}{ Firm consistency } \\
\hline Yes & $19(23.2)$ & $12(70.6)$ & & $16(22.2)$ & $10(55.6)$ & \\
\hline No & $63(76.8)$ & $5(29.4)$ & $<0.001$ & $56(77.8)$ & $8(44.4)$ & 0.005 \\
\hline \multicolumn{7}{|c|}{ Postoperative CSF leak } \\
\hline Yes & $4(4.9)$ & $2(11.8)$ & & $3(4.2)$ & $3(16.7)$ & \\
\hline No & 78 (95.1) & $15(88.2)$ & 0.279 & 69 (95.8) & 15 (83.3) & 0.057 \\
\hline \multicolumn{7}{|c|}{ Postoperative cranial nerve palsy } \\
\hline
\end{tabular}

PA, pituitary adenoma; CS, cavernous sinus; CSF, cerebrospinal fluid; GTR, gross total resection; STR, subtotal tumor resection. In bold: represent statistical significance.

TABLE 5 | Complications of cranial nerve palsy.

\begin{tabular}{|c|c|c|c|c|c|c|}
\hline & \multicolumn{3}{|c|}{ Postoperative } & \multicolumn{3}{|c|}{ Improvement during follow-up } \\
\hline CN III & 4 & 1 & 3 & 2 & 1 & 1 \\
\hline CN IV & 0 & 0 & 0 & 0 & 0 & 0 \\
\hline CN V & 0 & 0 & 0 & 0 & 0 & 0 \\
\hline CN VI & 3 & 1 & 2 & 1 & 1 & 0 \\
\hline
\end{tabular}

CN III, oculomotor nerve, CN IV, trochlear nerve, CN V, trigeminal nerve, CN VI, abducens nerve. 
TABLE 6 | Endocrine outcomes correlated with multiple potential variables.

\begin{tabular}{|c|c|c|c|}
\hline Variables & $\begin{array}{c}\text { Hormone remission } \\
\text { Yes }\end{array}$ & $\begin{array}{c}\text { Hormone remission } \\
\text { No }\end{array}$ & $\begin{array}{c}P \\
\text { Value }\end{array}$ \\
\hline \multicolumn{4}{|l|}{ Size of tumor } \\
\hline \multicolumn{4}{|c|}{ Volume of tumor(V, $\mathrm{cm} 3)$} \\
\hline$V<15$ & $6(75.0)$ & $2(25.0)$ & \\
\hline $15 \leq \mathrm{V} \leq 30$ & $11(78.6)$ & $3(21.4)$ & \\
\hline GTR & 16 (88.9) & $2(11.1)$ & \\
\hline STR & $11(68.7)$ & $5(31.3)$ & \\
\hline PTR & $2(33.3)$ & $4(66.7)$ & 0.028 \\
\hline \multicolumn{4}{|c|}{ Extent of CS resection } \\
\hline GTR & $18(75.0)$ & $6(25.0)$ & \\
\hline STR & $10(71.4)$ & $4(28.6)$ & \\
\hline
\end{tabular}

GTR, gross total resection; STR, subtotal tumor resection; PTR, partial tumor resection; CS, cavernous sinus.

In bold: represent statistical significance.

TABLE 7 | Visual outcomes correlated with multiple potential variables.

\begin{tabular}{|c|c|c|c|}
\hline Variables & Improved & Unchanged & $\begin{array}{c}P \\
\text { value }\end{array}$ \\
\hline \multicolumn{4}{|c|}{$\begin{array}{l}\text { Preoperative visual } \\
\text { symptoms }\end{array}$} \\
\hline Unilateral & $17(70.8)$ & $7(29.2)$ & \\
\hline Bilateral & 11(78.6) & $3(21.4)$ & 0.601 \\
\hline \multicolumn{4}{|l|}{ Size of tumor } \\
\hline Giant PA & 19(79.2) & $5(20.8)$ & \\
\hline$V<15$ & 12(80.0) & $3(20.0)$ & \\
\hline $15 \leq \mathrm{V} \leq 30$ & $9(69.2)$ & $4(31.8)$ & \\
\hline$>30$ & $7(70.0)$ & $3(30.0)$ & 0.774 \\
\hline \multicolumn{4}{|c|}{ Firm consistency } \\
\hline Yes & $9(60.0)$ & $6(40.0)$ & \\
\hline No & 19(82.6) & $4(17.4)$ & 0.122 \\
\hline \multicolumn{4}{|c|}{ Extent of CS resection } \\
\hline GTR & $20(83.3)$ & $4(16.7)$ & \\
\hline STR & $7(58.3)$ & $5(41.7)$ & \\
\hline PTR & $1(50.0)$ & $1(50.0)$ & 0.203 \\
\hline \multicolumn{4}{|c|}{ Tumor characteristics } \\
\hline Primary & 18(85.7) & $3(14.3)$ & \\
\hline Recurrent & 10(58.8) & $7(41.2)$ & 0.061 \\
\hline
\end{tabular}

PA, pituitary adenoma; GTR, gross tumor resection; STR, subtotal tumor resection; PTR, partial tumor resection.

In bold: represent statistical significance.

microscopy, and this is broadly consistent with the results of previously published endoscopic studies. The superior visual outcomes of endoscopic endonasal surgery reflect the ability of the endoscope to visualize and protect the optic apparatus and its blood supply in the subarachnoid space, which these tumors can sometimes invade. In our study, patients with a total resection were more likely to have visual improvement than those with incomplete resection.

\section{Endocrine Outcome}

In addition to removal of the tumor, hormone remission is an important indicator of surgical outcome for functional PAs. 
TABLE 8 | Comparison with similar studies of pituitary adenomas involving cavernous sinus published in the last decade.

\begin{tabular}{|c|c|c|c|c|c|c|c|c|}
\hline Author & Year & No. of cases & Grade 1 & Grade 2 & Grade 3 & Grade 4 (GTR \%) & GTR (\%) & Mean follow-up(m) \\
\hline Ceylan et al. (20) & 2010 & 19 & 0 & 0 & 9 & 10 (NR) & 63.2 & 26 \\
\hline Zhao et al. (21) & 2010 & 61 & 0 & 0 & 21 & $40(47.5)$ & 62.0 & 38 \\
\hline Paluzzi et al. (22) & 2013 & 403 & 105 & 142 & 81 & $75(0.0)$ & 64.1 & NR \\
\hline Taniguchi et al. (23) & 2015 & 25 & 0 & 0 & 23 & $2(0.0)$ & 56.0 & 36 \\
\hline Ferreli et al. (27) & 2015 & 56 & 0 & 0 & 28 & $28(17.8)$ & 30.3 & 61 \\
\hline Bao et al. (24) & 2015 & 52 & 0 & 0 & 13 & $39(53.8)$ & 63.5 & 24 \\
\hline Kalinin et al. (25) & 2016 & 97 & 11 & 22 & 23 & $41(\mathrm{NR})$ & 50.5 & NR \\
\hline Toda et al. (19) & 2018 & 30 & 0 & 0 & 0 & $30(10.0)$ & 10.0 & NR \\
\hline Kosugi et al. (26) & 2019 & 23 & 0 & 0 & 7 & $16(6.3)$ & 8.7 & NR \\
\hline Total & & 766 & 116 & 164 & 205 & 281 & & \\
\hline Present study & 2020 & 102 & 0 & 0 & 0 & $102(70.6)$ & 70.6 & 46 \\
\hline
\end{tabular}

NR, not reported; GTR, gross total resection.

Hofstetter et al. (30) reviewed 86 consecutive functional PAs (18 cases with CS invasion and 68 cases without CS invasion) by transsphenoidal endoscopy and the overall hormone remission rate was $60 \%$. Bao et al. (24) reported a study of 52 cases of PAs that had invaded the CS, including 25 cases of functional PAs. Among the functional PAs, the hormone remission rate was $76 \%$. In our study, among the 40 cases of functional PAs, the rate of hormone remission was $72.5 \%$, which is consistent with previous studies. Patients with GTR of the entire tumor were more likely to experience hormone remission than those with incomplete resection $(\mathrm{P}<0.05)$. Of note, in our study, the endocrine outcomes were difficult to compare with previous endoscopic studies, which included tumors that did not invade the CS or different extents of CS invasion, whereas our study only included grade 4 PAs.

PRL-secreting adenomas with CS invasion present a significant challenge to pharmacologic treatment. In our study, indications for surgery mainly included drug-resistant tumors and patients who experienced drug intolerance due to side effects. Residual tumors in the CS can continue to cause endocrinological symptoms, and tumors with CS invasion are more likely to develop drug resistance. In some patients, residual CS lesions may remain even after continued medical treatment $(31,32)$.

\section{Tumor Recurrence}

PAs are benign tumors, although they often invade surrounding structures such as the CS and the sphenoid sinus. For benign tumors, patients have a good prognosis if the tumor can be completely removed; on the contrary, incomplete tumor resection may result in tumor recurrence. Prior studies have reported that incomplete tumor resection leads to a high recurrence rate, as high as $40-70 \%(33,34)$. In contrast, the recurrence rate after GTR is significantly lower, with a $6-21 \%$ recurrence rate reported in the literature $(33,35)$. Notably, these studies include both invasive and non-invasive PAs, not just PAs invading the CS. Recently, Hwang et al. reported that up to $25 \%$ of cases with severe CS invasion recurred after total resection or near-total resection via a transsphenoidal endoscopic approach with long-term followup (11). In our study, 6 patients (5.9\%), including 4 patients with PTR, 1 with STR and 1 with GTR, experienced tumor recurrence. Compared with the results reported in previous literature, the tumor recurrence rate in our study was relatively low. It is more difficult to achieve GTR in recurrent tumors, due to the formation of tissue adhesion and scar tissue, and changes that can occur in the normal anatomical structure after the initial operation. Additionally, the possibility of intraoperative injury to the ICA and surrounding cranial nerves is significantly increased (36). This was also confirmed in our study. Therefore, it is particularly important to completely remove the tumor during the first operation.

\section{The Safety of Aggressive Tumor Resection Complications-ICA Injury}

ICA injury is the most serious complication of transsphenoidal endoscopic surgery and is the main obstacle to GTR within the CS. Because of this, many tumors within the CS are not aggressively removed. In practice, however, it is not impossible to avoid ICA injury. Accumulated evidence has shown that the incidence of ICA injury by the transsphenoidal approach to PAs is low, reportedly $0-1.6 \%(22,37-39)$. However, these studies include PAs with or without CS invasion. In one study, Raithatha et al. reported 41 cases of PAs involving CS that utilized transsphenoidal endoscopic surgery, and the incidence of ICA injury was $2.4 \%$ (40). In our study, among the 102 cases of grade 4 PAs, ICA injury occurred in 2 patients (1.9\%). Given the severity of risk with CS invasion, the incidence of ICA injury in our study appears to be favorable, compared with what has been previously reported. In our experience, the risk of ICA injury can be reduced by the following: 1) Performing a preoperative cerebral angiography balloon occlusion test to evaluate the compensatory capacity of the contralateral ICA in case of ipsilateral ICA injury; 2) Utilizing intraoperative navigation and doppler ultrasonography to assist in determining the position of the ICA in advance; 3) Exposing the proximal end of the ICA before entering the CS to remove the tumor; and 4) Using three-dimensional MRI to individually analyze the spatial relationship between the ICA and the CS tumor, and further, to determine the size of each compartment in the CS. After following these steps, and, according to the individual spatial relationship, it is possible to then decide the point of entry to the CS and the type of surgical approach to take within the CS. If the above four objectives are achieved, and intraoperative ICA injury 
still occurs, then it is imperative to restore it intraoperatively in the best way possible. Once injury occurs to the ICA, various methods, such as electrocoagulation of the vessel wall, clipping the proximal end of the ICA with an aneurysm clamp, or interventional therapy, can be adopted to manage the injury according to the extent of injury. For the 2 patients with ICA injury in our study, the injured ICA was completely clipped in one patient, and the ICA wall was electrocoagulated in the other patient. During the follow-up period, cerebral angiography was performed on the 2 patients, and for both, no pseudoaneurysm formation occurred, and no obvious symptoms were observed. Of note, both of these patients with intraoperative ICA injury had undergone previous operations for PAs. This also further demonstrates the importance of GTR at the first operation.

\section{Complications-Cranial Nerve Palsy}

Cranial nerve palsy is a common surgical complication of PAs with CS invasion, especially in the transcranial microscopic resection of CS tumors, because in traditional craniotomy, the CS is entered from the lateral wall of the CS, which is the exact location of multiple cranial nerves. In current transsphenoidal endoscopic surgical procedures, the CS is entered through the medial or anterior wall of the CS, which has no nerve structures. Therefore, the incidence of cranial nerve palsy is low by transsphenoidal endoscopy for the removal of PAs from the CS. Toda et al. reported a study of 30 patients who underwent transsphenoidal endoscopic surgery; the GTR rate of grade 4 PAs was $10 \%$ and the complication rate of cranial nerve palsy was $6.7 \%$ (19). Similarly, another transsphenoidal endoscopic study of 52 patients included 13 patients with grade 3 PAs and 39 patients with grade 4 PAs, and the incidence of cranial nerve palsy was $9.6 \%$ (24). These studies both show that cranial nerve palsy occurred mainly in the oculomotor and abducens nerves. In contrast, trochlear and trigeminal nerve palsy rarely occurred. In our study, new postoperative cranial nerve palsy was found in 7 cases $(6.8 \%)$, including 3 cases of abducens nerve palsy and 4 cases of oculomotor nerve palsy, which is consistent with the findings of previous literature. During the follow-up, improvement was observed in 3 of the 7 patients, including 1 case with abducens nerve palsy and 2 cases with oculomotor nerve palsy. As the oculomotor nerve is located in the oculomotor nerve triangle of the CS, damage to the oculomotor nerve can occur when removing the tumor from this area, especially a tumor that is invading the temporal lobe through the oculomotor nerve triangle. Of note, the oculomotor nerve triangle is often referred to as the blind area of transsphenoidal endoscopic surgery (41). Unlike the oculomotor nerve, the abducens nerve is not located on the lateral wall of the CS, but rather within the space of the CS and has adhesion connections with the ICA (12). During tumor resection, it is necessary to be familiar with the shape of the abducens nerve in the CS and to sharply separate adhesions from the ICA to reduce the incidence of injury to the abducens nerve. In our study, cranial nerve palsy occurred in 2 of the 60 patients (3.3\%) with primary PAs, compared with 5 of the 42 patients (11.9\%) with recurrent PAs. In order to avoid cranial nerve palsy for PAs with CS invasion, especially for recurrent PAs, it is necessary to monitor craniocerebral nerves, such as the oculomotor nerve and the abducens nerve, by means of intraoperative electrophysiological detection of extraocular muscle movement (42).

\section{Reasons for Aggressive Removal of Grade 4 PAs}

In our study, the GTR rate of Knosp grade 4 PAs was significantly higher than any previously published study. Additionally, patients maintained favorable visual function and endocrine outcomes, and had low recurrence rates. Far more importantly, for an experienced endoscopist, such an aggressive tumor resection strategy did not significantly increase the incidence of complications. This favorable surgical outcome is due to the recent significant improvement in the understanding of Knosp grade 4 PAs. A preoperative analysis of the individual spatial relationship among the ICA, the CS tumor, and various compartments of the CS, coupled with intraoperative assistive techniques such as neuronavigation, doppler ultrasonography and cranial nerve monitoring, have enabled us to aggressively pursue GTR. However, it is important to emphasize that a successful procedure requires extensive experience in transsphenoidal endoscopic surgery.

\section{CONCLUSIONS}

For experienced neuroendoscopists, an aggressive tumor resection strategy via transsphenoidal endoscopic surgery may be an effective and safe option for Knosp grade 4 PAs.

\section{DATA AVAILABILITY STATEMENT}

The original contributions presented in the study are included in the article/supplementary material. Further inquiries can be directed to the corresponding author.

\section{ETHICS STATEMENT}

The studies involving human participants were reviewed and approved by the Institutional Ethics Committee of the First Affiliated Hospital of Nanchang University. The patients/ participants provided their written informed consent to participate in this study.

\section{AUTHOR CONTRIBUTIONS}

Conception and design: TO and TH. Acquisition of data: JL, FZ, and LX. Analysis and interpretation of data: NZ, SX, and BW. Drafting the article: TO. Critically revising the article: DZ and BT. Reviewed submitted version of manuscript: TH. Approved the final version of the manuscript on behalf of all authors: $\mathrm{TH}$. Statistical analysis: SX. Study supervision: TH, DZ, and ML. All authors contributed to the article and approved the submitted version. 


\section{FUNDING}

The present study was supported by the National Natural Science Foundation of China (grant no. 81760447; grant no. 81960247,

\section{REFERENCES}

1. Ostrom QT, Gittleman H, Farah P, Ondracek A, Chen Y, Wolinsky Y, et al. CBTRUS Statistical Report: Primary Brain and Central Nervous System Tumors Diagnosed in the United States in 2006-2010. Neuro Oncol (2013) 15 Suppl 2(Suppl 2):ii1-56. doi: 10.1093/neuonc/not151. Erratum in: Neuro Oncol (2014) 16(5):760.

2. Aflorei ED, Korbonits M. Epidemiology and Etiopathogenesis of Pituitary Adenomas. J Neurooncol (2014) 117:379-94. doi: 10.1007/s11060-013-1354-5

3. Knosp E, Steiner E, Kitz K, Matula C. Pituitary Adenomas With Invasion of the Cavernous Sinus Space: A Magnetic Resonance Imaging Classification Compared With Surgical Findings. Neurosurgery (1993) 33:610-617; discussion 617-618. doi: 10.1227/00006123-199310000-00008

4. Cottier JP, Destrieux C, Brunereau L, Bertrand P, Moreau L, Jan M, et al. Cavernous Sinus Invasion by Pituitary Adenoma: MR Imaging. Radiology (2000) 215:463-9. doi: 10.1148/radiology.215.2.r00ap18463

5. Pontius AT, Ducic Y. Extended Orbitozygomatic Approach to the Skull Base to Improve Access to the Cavernous Sinus and Optic Chiasm. Otolaryngol Head Neck Surg (2004) 130:519-25. doi: 10.1016/j.otohns.2004.01.013

6. Spallone A, Vidal RV, Gonzales JG. Transcranial Approach to Pituitary Adenomas Invading the Cavernous Sinus: A Modification of the Classical Technique to be Used in a Low-Technology Environment. Surg Neurol Int (2010) 1:25. doi: 10.4103/2152-7806.65054

7. Dallapiazza R, Bond AE, Grober Y, Louis RG, Payne SC, Oldfield EH, et al. Retrospective Analysis of a Concurrent Series of Microscopic Versus Endoscopic Transsphenoidal Surgeries for Knosp Grades 0-2 Nonfunctioning Pituitary Macroadenomas at a Single Institution. J Neurosurg (2014) 121:511-7. doi: 10.3171/2014.6.jns131321

8. Fathalla H, Cusimano MD, Di Ieva A, Lee J, Alsharif O, Goguen J, et al. Endoscopic Versus Microscopic Approach for Surgical Treatment of Acromegaly. Neurosurg Rev (2015) 38:541-548; discussion 548-549. doi: 10.1007/s10143-015-0613-7

9. Gaillard S. The Transition From Microscopic to Endoscopic Transsphenoidal Surgery in High-Caseload Neurosurgical Centers: The Experience of Foch Hospital. World Neurosurg (2014) 82:S116-120. doi: 10.1016/j.wneu.2014. 07.033

10. Koutourousiou M, Gardner PA, Fernandez-Miranda JC, Paluzzi A, Wang EW, Snyderman CH. Endoscopic Endonasal Surgery for Giant Pituitary Adenomas: Advantages and Limitations. J Neurosurg (2013) 118:621-31. doi: 10.3171/2012.11.jns121190

11. Hwang J, Seol HJ, Nam DH, Lee JI, Lee MH, Kong DS. Therapeutic Strategy for Cavernous Sinus-Invading Non-Functioning Pituitary Adenomas Based on the Modified Knosp Grading System. Brain Tumor Res Treat (2016) 4:639. doi: 10.14791/btrt.2016.4.2.63

12. Fernandez-Miranda JC, Zwagerman NT, Abhinav K, Lieber S, Wang EW, Snyderman CH, et al. Cavernous Sinus Compartments From the Endoscopic Endonasal Approach: Anatomical Considerations and Surgical Relevance to Adenoma Surgery. J Neurosurg (2018) 129:430-41. doi: 10.3171/ 2017.2.JNS162214

13. Wu X, Xie SH, Tang B, Yang YQ, Yang L, Ding H, et al. Pituitary Adenoma With Posterior Area Invasion of Cavernous Sinus: Surgical Anatomy, Approach, and Outcomes. (2020). doi: 10.1007/s10143-020-01404-1

14. Casanueva FF, Molitch ME, Schlechte JA, Abs R, Bonert V, Bronstein MD, et al. Guidelines of the Pituitary Society for the Diagnosis and Management of Prolactinomas. Clin Endocrinol (2006) 65:265-73. doi: 10.1111/j.13652265.2006.02562.x

15. Katznelson L, Laws ERJr., Melmed S, Molitch ME, Murad MH, Utz A, et al. Acromegaly: An Endocrine Society Clinical Practice Guideline. J Clin Endocrinol Metab (2014) 99:3933-51. doi: 10.1210/jc.2014-2700

16. Nieman LK, Biller BM, Findling JW, Murad MH, Newell-Price J, Savage MO, et al. Treatment of Cushing's Syndrome: An Endocrine Society Clinical grant no. 82060246), Project of Science and Technology Department of Jiangxi Province (grant no. 20192BBG70026, grant no. S2019QNJJB1056), and Jiangxi Provincial Education Department Project (grant no. GJJ180054; grant no. GJJ180116).
Practice Guideline. J Clin Endocrinol Metab (2015) 100:2807-31. doi: $10.1210 /$ jc.2015-1818

17. Melmed S, Bronstein MD, Chanson P, Klibanski A, Casanueva FF, Wass JAH, et al. A Consensus Statement on Acromegaly Therapeutic Outcomes. Nat Rev Endocrinol (2018) 14:552-61. doi: 10.1038/s41574-018-0058-5

18. Woodworth GF, Patel KS, Shin B, Burkhardt JK, Tsiouris AJ, McCoul ED, et al. Surgical Outcomes Using a Medial-to-Lateral Endonasal Endoscopic Approach to Pituitary Adenomas Invading the Cavernous Sinus. J Neurosurg (2014) 120:1086-94. doi: 10.3171/2014.1.jns131228

19. Toda M, Kosugi K, Ozawa H, Ogawa K, Yoshida K. Surgical Treatment of Cavernous Sinus Lesion in Patients With Nonfunctioning Pituitary Adenomas Via the Endoscopic Endonasal Approach. J Neurol Surg Part B Skull Base (2018) 79:S311-5. doi: 10.1055/s-0038-1667123

20. Ceylan S, Koc K, Anik I. Endoscopic Endonasal Transsphenoidal Approach for Pituitary Adenomas Invading the Cavernous Sinus. J Neurosurg (2010) 112:99-107. doi: 10.3171/2009.4.jns09182

21. Zhao B, Wei YK, Li GL, Li YN, Yao Y, Kang J, et al. Extended Transsphenoidal Approach for Pituitary Adenomas Invading the Anterior Cranial Base, Cavernous Sinus, and Clivus: A Single-Center Experience With 126 Consecutive Cases. J Neurosurg (2010) 112:108-17. doi: 10.3171/ 2009.3.JNS0929

22. Paluzzi A, Fernandez-Miranda JC, Tonya Stefko S, Challinor S, Snyderman $\mathrm{CH}$, Gardner PA. Endoscopic Endonasal Approach for Pituitary Adenomas: A Series of 555 Patients. Pituitary (2014) 17:307-19. doi: 10.1007/s11102-0130502-4

23. Taniguchi M, Hosoda K, Akutsu N, Takahashi Y, Kohmura E. Endoscopic Endonasal Transsellar Approach for Laterally Extended Pituitary Adenomas: Volumetric Analysis of Cavernous Sinus Invasion. Pituitary (2015) 18:518-24. doi: 10.1007/s11102-014-0604-7

24. Bao X, Deng K, Liu X, Feng M, Chen CC, Lian W, et al. Extended Transsphenoidal Approach for Pituitary Adenomas Invading the Cavernous Sinus Using Multiple Complementary Techniques. Pituitary (2016) 19:1-10. doi: 10.1007/s11102-015-0675-0

25. Kalinin PL, Sharipov OI, Pronin IN, Kutin MA, Fomichev DV, Kadashev BA, et al. Endoscopic Transsphenoidal Resection of Pituitary Adenomas Invading the Cavernous Sinus. Zh Vopr Neirokhir Im N N Burdenko (2016) 80:63-74. doi: 10.17116/neiro201680463-74

26. Kosugi K, Tamura R, Mase T, Tamura H, Jinzaki M, Yoshida K, et al Relationship Between Pneumatization of Lateral Recess in the Sphenoid Sinus and Removal of Cavernous Sinus Invasion in Pituitary Adenomas by Endoscopic Endonasal Surgery. Surg Neurol Int (2019) 10:222. doi: 10.25259/SNI_169 2019

27. Ferreli F, Turri-Zanoni M, Canevari FR, Battaglia P, Bignami M, Castelnuovo $\mathrm{P}$, et al. Endoscopic Endonasal Management of non-Functioning Pituitary Adenomas With Cavernous Sinus Invasion: A 10- Year Experience. Rhinology (2015) 53:308-16. doi: 10.4193/Rhin14.309

28. Chabot JD, Chakraborty S, Imbarrato G, Dehdashti AR. Evaluation of Outcomes After Endoscopic Endonasal Surgery for Large and Giant Pituitary Macroadenoma: A Retrospective Review of 39 Consecutive Patients. World Neurosurg (2015) 84:978-88. doi: 10.1016/j.wneu.2015.06.007

29. Komotar RJ, Starke RM, Raper DM, Anand VK, Schwartz TH. Endoscopic Endonasal Compared With Microscopic Transsphenoidal and Open Transcranial Resection of Giant Pituitary Adenomas. Pituitary (2012) 15:150-9. doi: 10.1007/s11102-011-0359-3

30. Hofstetter CP, Shin BJ, Mubita L, Huang C, Anand VK, Boockvar JA, et al. Endoscopic Endonasal Transsphenoidal Surgery for Functional Pituitary Adenomas. Neurosurg Focus (2011) 30:E10. doi: 10.3171/2011.1.FOCUS10317

31. Hamilton DK, Vance ML, Boulos PT, Laws ER. Surgical Outcomes in Hyporesponsive Prolactinomas: Analysis of Patients With Resistance or Intolerance to Dopamine Agonists. Pituitary (2005) 8:53-60. doi: 10.1007/ s11102-005-5086-1 
32. Wu ZB, Su ZP, Wu JS, Zheng WM, Zhuge QC, Zhong M. Five Years Follow-Up of Invasive Prolactinomas With Special Reference to the Control of Cavernous Sinus Invasion. Pituitary (2008) 11:63-70. doi: 10.1007/s11102-007-0072-4

33. Santoro A, Minniti G, Ruggeri A, Esposito V, Jaffrain-Rea ML, Delfini R. Biochemical Remission and Recurrence Rate of Secreting Pituitary Adenomas After Transsphenoidal Adenomectomy: Long-Term Endocrinologic FollowUp Results. Surg Neurol (2007) 68:513-518. doi: 10.1016/j.surneu.2007.05.057

34. Cappabianca P, Solari D. The Endoscopic Endonasal Approach for the Treatment of Recurrent or Residual Pituitary Adenomas: Widening What to See Expands What to do? World Neurosurg (2012) 77:455-6. doi: 10.1016/ j.wneu.2011.08.047

35. Chang EF, Zada G, Kim S, Lamborn KR, Quinones-Hinojosa A, Tyrrell JB, et al. Long-Term Recurrence and Mortality After Surgery and Adjuvant Radiotherapy for Nonfunctional Pituitary Adenomas. J Neurosurg (2008) 108:736-45. doi: 10.3171/JNS/2008/108/4/0736

36. Chang EF, Sughrue ME, Zada G, Wilson CB, Blevins LSJr., Kunwar S. Long Term Outcome Following Repeat Transsphenoidal Surgery for Recurrent Endocrine-Inactive Pituitary Adenomas. Pituitary (2010) 13:223-9. doi: 10.1007/s11102-010-0221-z

37. Dehdashti AR, Ganna A, Karabatsou K, Gentili F. Pure Endoscopic Endonasal Approach for Pituitary Adenomas: Early Surgical Results in 200 Patients and Comparison With Previous Microsurgical Series. Neurosurgery (2008) 62:1006-15. doi: 10.1227/01.neu.0000325862.83961.12

38. Frank G, Pasquini E, Farneti G, Mazzatenta D, Sciarretta V, Grasso V, et al. The Endoscopic Versus the Traditional Approach in Pituitary Surgery. Neuroendocrinology (2006) 83:240-8. doi: 10.1159/000095534
39. Gondim JA, Schops M, de Almeida JP, de Albuquerque LA, Gomes E, Ferraz T, et al. Endoscopic Endonasal Transsphenoidal Surgery: Surgical Results of 228 Pituitary Adenomas Treated in a Pituitary Center. Pituitary (2010) 13:6877. doi: 10.1007/s11102-009-0195-x

40. Raithatha R, McCoul ED, Woodworth GF, Schwartz TH, Anand VK. Endoscopic Endonasal Approaches to the Cavernous Sinus. Int Forum Allergy Rhinol (2012) 2:9-15. doi: 10.1002/alr.20097

41. Goel A, Nadkarni T, Muzumdar D, Desai K, Phalke U, Sharma P. Giant Pituitary Tumors: A Study Based on Surgical Treatment of 118 Cases. Surg Neurol (2004) 61:436-45. doi: 10.1016/j.surneu.2003.08.036

42. Kitano M, Taneda M, Shimono T, Nakao Y. Extended Transsphenoidal Approach for Surgical Management of Pituitary Adenomas Invading the Cavernous Sinus. J Neurosurg (2008) 108:26-36. doi: 10.3171/jns/2008/108/ $01 / 0026$

Conflict of Interest: The authors declare that the research was conducted in the absence of any commercial or financial relationships that could be construed as a potential conflict of interest.

Copyright (C) 2021 Ouyang, Zhang, Xie, Tang, Li, Xiao, Zhang, Wu, Zhou, Li and Hong. This is an open-access article distributed under the terms of the Creative Commons Attribution License (CC BY). The use, distribution or reproduction in other forums is permitted, provided the original author(s) and the copyright owner(s) are credited and that the original publication in this journal is cited, in accordance with accepted academic practice. No use, distribution or reproduction is permitted which does not comply with these terms. 